\title{
Test plot study of a tailings stack final cover prototype
}

\author{
Germán Javier Rodari Gutierrez ${ }^{1}$, and Luciano Agustín Oldecop ${ }^{1}$ \\ ${ }^{1}$ Earthquake Research Institute, National University of San Juan, Libertador Av. 1290, San Juan, Argentina.
}

\begin{abstract}
Waste storage facilities must be protected against weathering once mining operations come to end, in order to ensure structural integrity and to avoid environmental pollution. Cover systems consisting on earthen materials layers that are placed over the wastes are a widely spread solution to fulfil such requirement. This paper presents an experimental study of a cover system intended to protect a waste storage facility study case located in the arid eastern foothills of the Central Andes range, Argentina. At the study case, filtered tailings and waste rock are stored conjunctly. Both materials are stacked as alternating layers, roughly one-meter thickness each. The cover prototype is comprised of the stack topmost tailings layer, which is expected to act as the store-and-release element of a WB cover. The prototype design also includes a waste rock layer placed on top of the tailings, to avoid wind and runoff erosion. A total of 6 study plots have been setup, each equipped with water content and matric suction sensors. The plots location was decided to tackle cover response under sloping and horizontal ground conditions. The performance of three different waste rock layer thicknesses are being studied under both placement inclinations. Available data shows that the prototype comprising a $10 \mathrm{~cm}$ thick waste rock layer has served satisfactorily to avoid deep percolation and tailings erosion.
\end{abstract}

\section{Introduction}

This paper presents the set-up and preliminary results of a test plot investigation designed to study the performance of a prototype water-balance type final cover for a filtered tailings storage facility, located in an arid and seismically active site.

Tailings are a waste material originated after the separation of valuable materials from ore rock, comprised of ground rock, water and residual amounts of chemical reagents. Tailings are considered hazardous wastes, due to the fact they often contain heavy metals that may be leachate or are capable of producing acid drainage when exposed to weathering. Preventing precipitation water from percolating into tailings, which is essential for contaminating avoidance once mining operations come to end, is achieved by means of engineering barriers known as final covers systems.

Final covers systems consist of one or more earthen materials layers that are spread over the wastes, sometimes including geo-membranes. The layers of a cover system can be tailored to achieve low permeability, thus favouring surface runoff and precluding infiltration. On the other hand, cover systems can be designed to control infiltration and temporary store precipitation near the surface, thus allowing for its later readily removal by means of evaporation and/or transpiration. The latter are frequently termed as store and release (SR) or water balance (WB) covers. Beside the avoidance of percolation, final covers may have to achieve additional objectives, imposed by the nature of the wastes, the topographic features of the tailings deposits, the site climate and specific mining industry regulations. Among others, controlling wastes migration due to surface water and wind are common goals of most final cover designs.

The water content of the tailings at the output of the processing plant is a key property, defining the hydromechanical response of these wastes. It conditions the whole management and disposal processes to a point where the available technologies are designated on the basis of the consistency of these wastes, i.e., fluid, thickened, paste and filtered tailings.

Reducing the amount of water discharged and stored along with the solid wastes poses multiple advantages, namely the free water management is simplified or eliminated and contaminating leakages and internal erosion damage of retaining structures risks are reduced, seismic behaviour of disposal facilities is enhanced.

Where feasible, filtration of tailings allows reaching typical water contents ranging from 20 to $45 \%$ (Wang et al 2014 [1]). Filtered tailings have a wet soil-like consistency, so their hauling and spreading at the storage facilities is done by means of conveyors belts or trucks and earthmoving equipment. Under favourable climate and appropriate management, filtered tailings can be stored at unsaturated state. The improvement of mechanical properties arising from suction enables the filtered tailings storage in stacks, with no need of containment structures. Moreover, the unsaturated condition precludes liquefaction, which is an interesting upgrade for seismically active locations. Since the stability of these storage facilities partially relay on unsaturated state, preventing the infiltration of rain or

\footnotetext{
Corresponding author: germanrodari@unsj.edu.ar
} 
snowmelt water and recharge of the already disposed filtered tailings is as important at any stage of the stacks building as it is at the final closure stage.

At the study case site, the storage of tailings was done in conjunction with rock waste, by stacking alternated layers of both materials, roughly one-meter thickness each.

The layered design aimed to ensure proper traffic conditions for trucks and earth moving equipment, since bearing capacity of recently disposed tailings was expected to be low. Besides, the coarse layers allow water drainage and avoid pore pressure build-up due to eventual disposal of excessively wet tailings arising from filtration plant missfunctions. Moreover, the pore size contrast between both stored wastes was expected to give raise to capillary barrier effect, consequently improving the water storage capacity of any of the tailings layers (Hillel 1971 [2], Stormont and Morris 1998 [3], Khire et al. 2000 [4]).

The climate in the case study area is arid, with strong water deficit. Average annual precipitation ranges between 100 and $200 \mathrm{~mm}$ (Cravero et al, 2017 [5]), while average annual potential evapotranspiration in the area has been estimated at $1276 \mathrm{~mm}$ (Oldecop et al, 2010 [6]). The strongest rainfall typically occurs during summer, as short and intense storms. Snowfalls are rare and snow accumulation seldom exceeds $5 \mathrm{~cm}$.

The final cover prototype presented in this work seizes the storage intrinsically available capillary barrier effect and the strong water deficit of the mine site. The main design hypothesis of the prototype is that the stack topmost tailings layer is capable of preventing the percolation of precipitating water by acting as the storeand-release layer of WB cover.

The latter statement is based on the conclusions of a previous experimental study (Oldecop et al, 2017 [7]), were the storage capacity of the tailings was investigated by using soil-column devices to record the evolution of water content profiles of two test specimens exposed to the weather conditions of the same tailings stack study case. One of the specimens consisted in two tailings layers separated by a waste rock layer, while the other one was comprised of a homogeneous tailings layer. The recorded water content profiles showed that the tailings beneath the waste rock layer remained isolated from surface conditions, while water from precipitations was able to penetrate the full depth of the homogenous tailings layer specimen. The storage capacity of the tailings layer placed over the waste rock after 14 month of site climate exposure was measured trough an artificial rain event. It resulted to be of about $200 \mathrm{~mm}$ for a $1 \mathrm{~m}$ thickness layer.

In order to control tailings migration due to wind and water run-off, the final cover prototype is completed by a layer of non-acid-generating waste rock placed on top of the topmost tailings layer.

Though available experimental data conduce to expect a suitable behaviour of tailings at acting as the store-and-release layer of the proposed cover, how much the erosion protective layer will interfere with the evaporation process, which is essential to pull out the rainfall water eventually stored in the topmost tailings layer, is unknown. In addition to prevent tailings migration, the thickness of the rock waste layer must also satisfy durability requirements. The experimental study presented herein is designed to record the performance of the final cover system comprised by an erosion protective waste rock layer and the already existing topmost tailing at controlling infiltration. Three different waste rock layers thickness are considered, in order to provide information yielding the optimal value.

\section{Experimental setup}

The cover prototype adopted is studied by means of in situ test plots. Three of these plots are located on the crest of the tailings stack, by the shoulder of the slope, while the remaining three are located on the adjacent slope, between the crest and the first berm, aiming to take into account sloping ground influence. Figure 1 shows plots locations and dimensions.

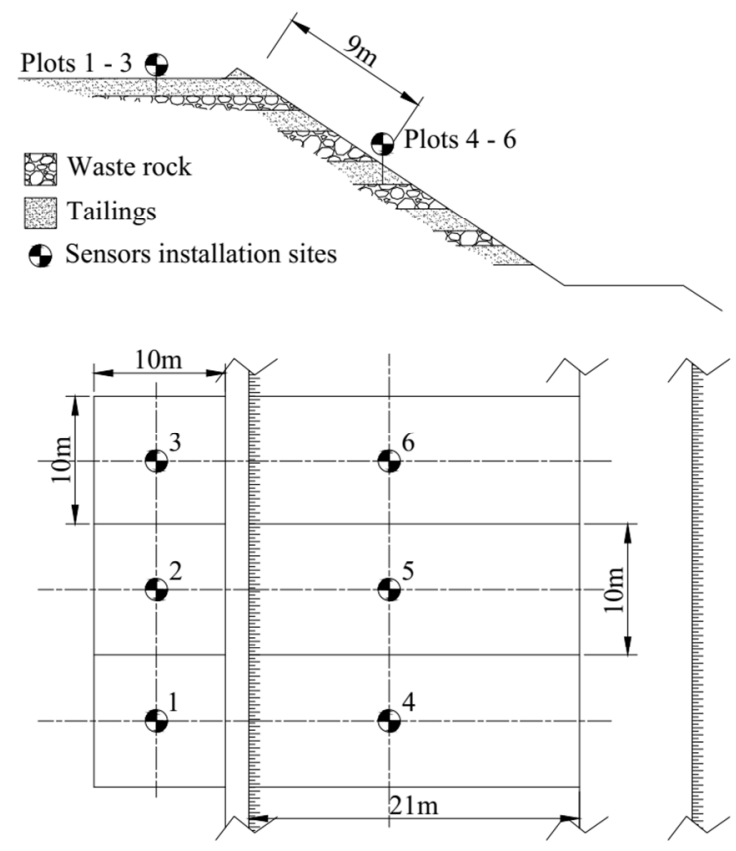

Fig. 1. Test plots location.

\subsection{Materials}

The test employs tailings that were already placed at the stack. Laboratory characterization of these wastes yielded ML classification, according to SUCS. Grain size distribution comprises $28 \%$ of fine sands, $71 \%$ of silt size particles and negligible content of clay size particles.

The waste rock for the erosion protective layer is a coarse angular gravel, with varying fines content and presence of blocks up to $0.50 \mathrm{~m}$ size. It comes from the underground mine excavation. No laboratory characterization of underground mine waste rock is available yet. Author's previous investigation on waste rock from pit excavation (Oldecop et al, 2017) [7] shows 
strong particle size distribution variation attributed to ore changing conditions. Figure 2 shows tailings particle size distribution. For the sake of comparison the granulometric curve of waste rock from open pit is also depicted in the Figure 2.

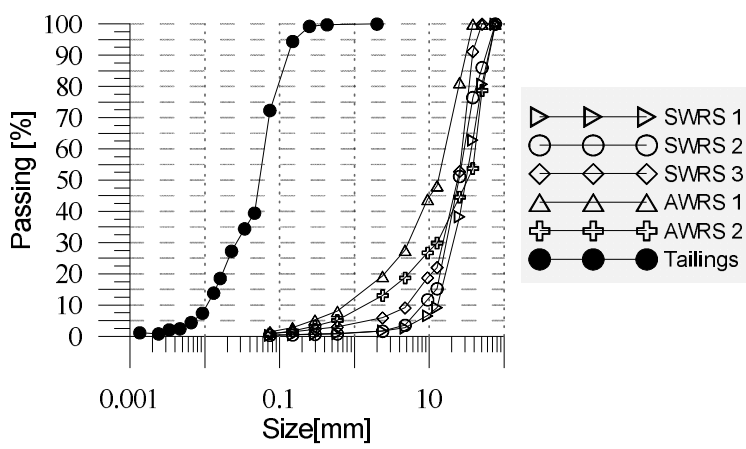

Fig. 2. Granulometric curves of altered pit waste rock (AWR) sane pit waste rock (SWR) and tailings.

\subsection{Test setup}

Plots 1 to 3 are each equipped with two Decagon 5TE volumetric water content sensors (VWC) (Meter Group 2019) [8], two Decagon MPS6 matric suction (S) sensors and a device intended to collect store and measure the water from percolation $(\mathrm{P})$, which will occur if the storage capacity of the tailings layer is exceeded. It is worth noting that MPS6 sensors are now named Teros 21 (Meter Group 2020) [9]. Notwithstanding, the MPS6 denomination will be held troughout this paper. Prior to sensors installation the plots area was levelled to obtain a horizontal surface, by hauling and spreading tailings from the nearby. The sensors were installed at $1.2 \mathrm{mx}$ $1 \mathrm{~m}$ trenches, excavated in each plot tailings until reaching the underlying rock waste layer. Firstly, percolating water measurement devices were embedded into the rock waste, making the upper edge of the collection trays to flush with the bottom level of the topmost tailings layers. Then, the trays were filled from bottom to top with coarse sand, fine gravel and hand selected rock waste respectively, intending to recreate the tailings - rock waste interface previous conditions, and also to keep tailings from eventually clogging the percolation measuring device. Finally, the VWC and S sensors were embedded at the centre of each excavation at the depths shown in Figure 3, as the trenches were refilled with the previously removed tailings.

Plots 4 to 6 are each equipped with two Decagon 5TE VWC sensors and two Decagon MPS6 S sensors. For sensor installation a trench was excavated at each plot site. The 5TE sensors were installed by inserting them into the front wall of trenches. The MPS6 sensors were installed into borings performed from the top of the tailings layers. Care was taken to achieve optimal contact between the sensors porous stone and the tailings. Finally, the trenches were filled with tailings and rock waste, to regain conditions prevailing before sensors installation. Figure 4 shows plots 4 to 6 typical sensor installation. During the test set up the apparent density and water content determinations were performed at plots 4 to 6 , in order to adjust the VWC readings. No samples were taken from plots 1 to 3 for VWC readings adjustment since the tailings were wetted and compacted after sensors placement. Consequently, the tailings original texture was lost and consolidation deformations were expected.

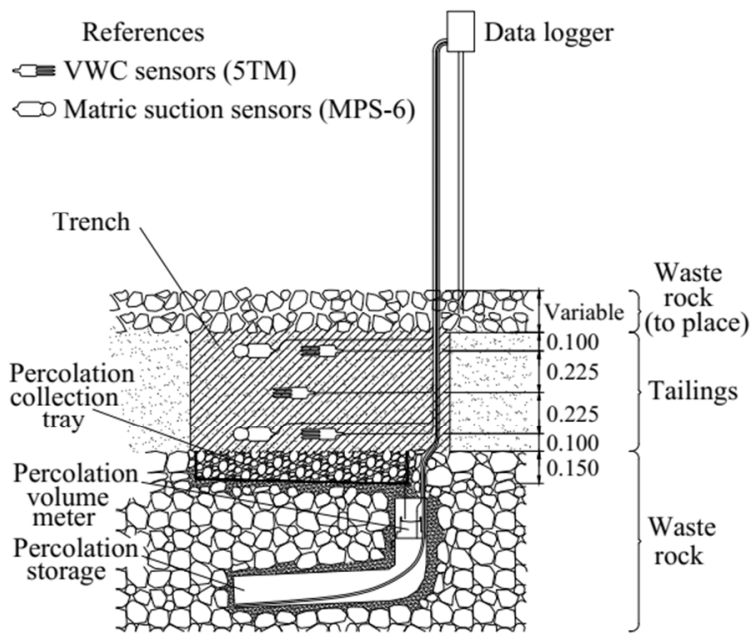

Fig. 3. Plots 1 to 3 typical installation.

References

$\therefore$ VWC sensors (5TM)

$\sqsubset$ Matric suction sensors (MPS-6)

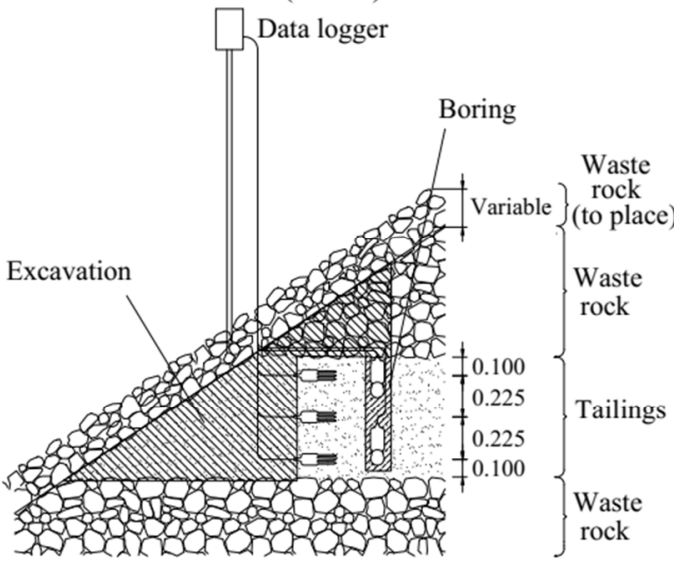

Fig. 4. Plots 4 to 6 typical installation.

48 days after the sensors were installed a flooding test was carried out, in order to check that no shrinkage cracking was induced after consolidation. Cracks development would have create preferential flow paths, thus keeping tailings from storing precipitations water as planned. Flooding was done by pouring a known water volume into ring bunds made from tailings, enclosing the $1.2 \mathrm{~m} \times 1 \mathrm{~m}$ areas where sensors were installed. The equivalent precipitated height for each plot was added to the rainfall record of the weather station shown in Figures 5 to 7 .

On the 117th day after the test setup, plots 1 to 3 were covered with waste rock layers, $1,0.5$ and $0.10 \mathrm{~m}$ thick respectively. Due to material availability at that 
time, only a portion of the total planned area was covered. Before waste rock was placed tailings apparent dry density was determined. Also samples were collected for water content determinations. Finally, on the 186th day after the test set up, the cover was completed on plots 1 to 3 . Also plots 4 to 6 were covered with waste rock layers, $1,0.5$ and $0.10 \mathrm{~m}$ thick respectively.

\section{Results}

Figures 5 to 10 shows the water content, matric suction and tailings temperature evolution recorded at each plot during the period 30/11/19 - 27/02/2020. These figures also depict cumulative rain. It is worth noting that precipitation records are discontinuous, due to weather station miss functions. Matric suction recordings from plots 1 to 3 corresponding to the period elapsed between sensors installation and flooding test are not available, due to data logger initial misconfiguration. VWC readings were adjusted on the basis of density and water content determinations performed during test set up (plots 4 to 6 ) or prior to flooding test (plots 1 to 3 ). Suction readings were corrected following the procedure proposed by Walthert \& Schleppi (2018) [10] in order to reduce temperature dependency of Decagon MPS6 sensors. The placement of the erosion protective waste rock layer is highlighted in figures 5 to 10 .

The test period started during late spring of 2018. The overall water content recorded at plots 1 to 3 decreased until the test 117 th day, when the erosion protective waste rock layer was partially placed.

Immediately after flooding, test suction recorded at $10 \mathrm{~cm}$ depth at plots 1 to 3 dropped suddenly, thus suggesting that the upper portion tailings reached saturation. Notwithstanding, VWC recorded at plots 1 and 2 at the same depth reached a peak value corresponding to $80 \%$ saturation after flooding. The VWC located at the same depth at plot 3 stopped working, so superficial VWC evolution after flooding test is missing in figure 7.

Sensors located at 32.5 and $55 \mathrm{~cm}$ depth in plot 1 recorded no noticeable VWC change after flooding. In turn, at plots 2 and 3 the effect of flooding test is clearly recorded by sensors located at the same depth. Suction measured at $55 \mathrm{~cm}$ below the surface of plot 1 is moderately reduced after the flooding test, reaching a minimum with a delay of 6 days. In contrast, in plots 2 and 3 the suction drop recorded at the same depth is significantly higher than in plot 1 , reaching minimum values 4 days after the flooding test. This groundwater flow behaviour dissimilarity between plot 1 and plots 2 and 3 holds after every rain event until rock waste layer is partially placed, and is attributed to tailings initial water content and density heterogeneities arising from sensors installation method employed for plots 1 to 3 .

By the time plots 1 to 3 were partially covered with rock waste, VWC at each level of all the 3 plots had reached an absolute minimum since test started, thus implying that water infiltrated into the tailings layer due to flooding test and later rain events was completely evaporated within a 70 days lapse.
After waste rock partial placement the drying process at plots 1 and 2 suddenly ceased. Instead, records from both plots show that VWC at $10 \mathrm{~cm}$ depth slightly increases while at $32.5 \mathrm{~cm}$ and $55 \mathrm{~cm}$ depth VWC decreases, thus suggesting an ongoing water content redistribution.

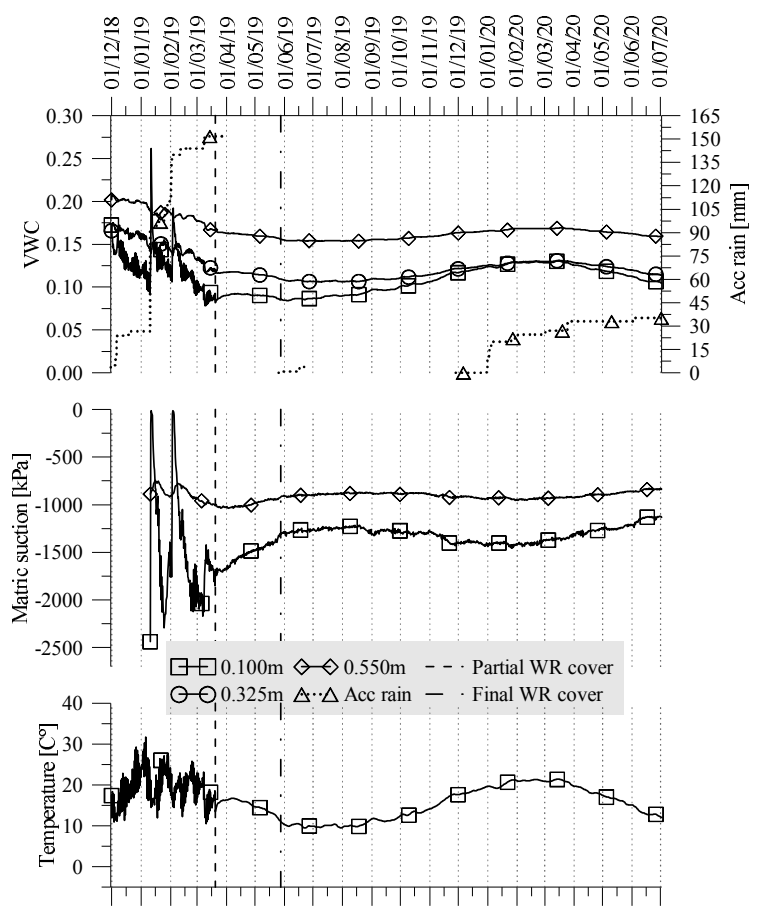

Fig. 5. Time evolution of VWC, matric suction and temperature recorded at different depths of Plot 1

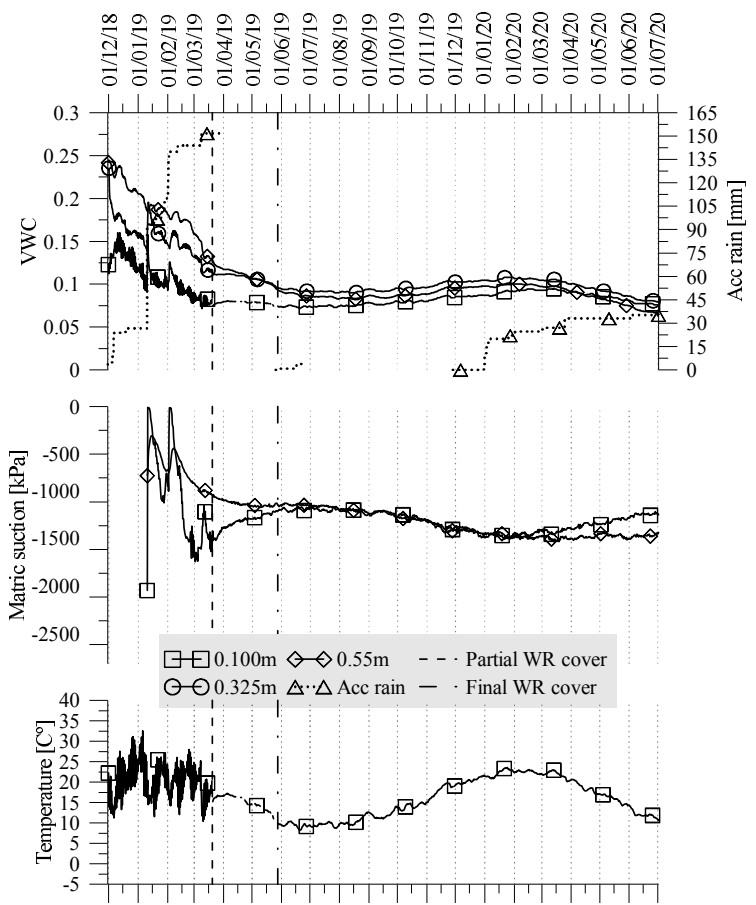

Fig. 6. Time evolution of VWC, matric suction and temperature recorded at different depths of Plot 2 
Suction records at plots 1 and 2 tend to decrease and tailings temperature daily fluctuation is arrested. In contrast, rock waste partial placement over plot 3 seems not to affect the previously recorded tailings drying trend. The VWC reduction rate since then is comparable to that of the foregoing period. Tailings temperature daily fluctuation at plot 3 is not arrested by waste rock partial placement tough is appreciably attenuated. The conclusion of rock waste placement over plots 1 to 3 produced no sensitive effect on records from plots 1 to 3 .

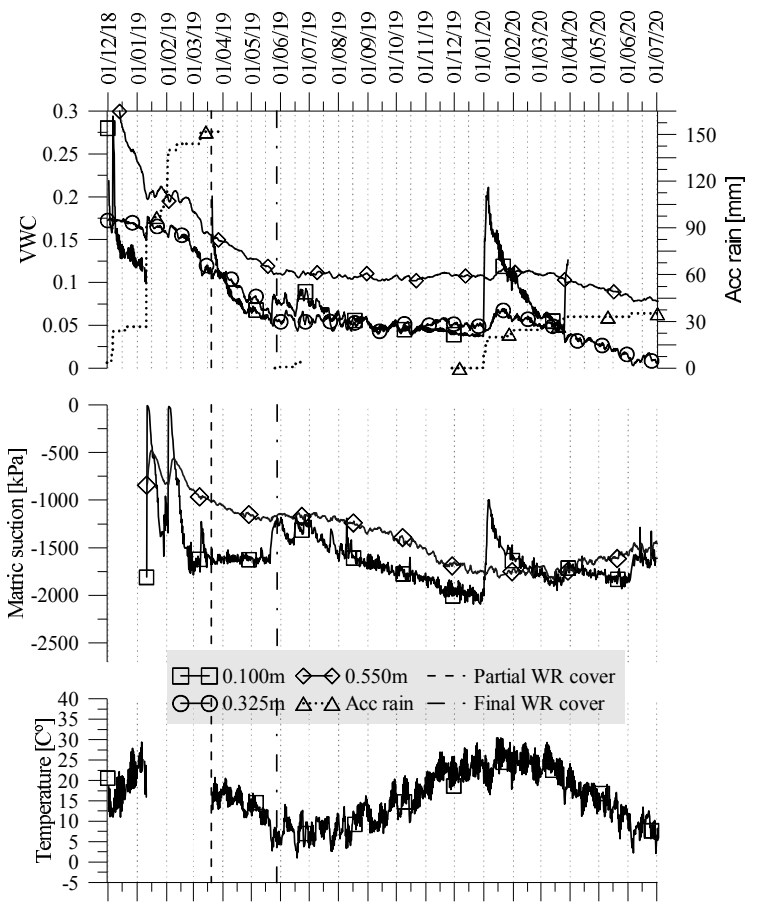

Fig. 7. Time evolution of VWC, matric suction and temperature recorded at different depths of Plot 3

From January 1 and 5 of 2020 a total rain of $22 \mathrm{~mm}$ was precipitated. The effect of these summer storms is apparent in records from plot 3 . VWC recorded at $10 \mathrm{~cm}$ raised immediately after the first event, while VWC at $32.5 \mathrm{~cm}$ and $55 \mathrm{~cm}$ depth reached maximum values with delays of 15 and 25 days respectively. After peak values are reached, a drying process is observed in all three VWC sensors, with VWC reduction rate comparable to that observed after the test assembly or after flooding test.

Suction, VWC and temperature recorded at tailings from plot 4 to 6 behaved largely different from those of the plots located at the top of the stack. Measures of these parameters remain practically constant throughout the recording. No alterations are seen after the rock waste placement, nor are significant changes seen as a result of rainfall before or after rock waste placement.

No VWC change is recorded as a response of plots 1 and 2 to rain events precipitated during winter of 2019 . In contrast, the same rain events produced VWC rising at plot 3 , though this effect was only recorded by sensors located a $10 \mathrm{~cm}$ depth.

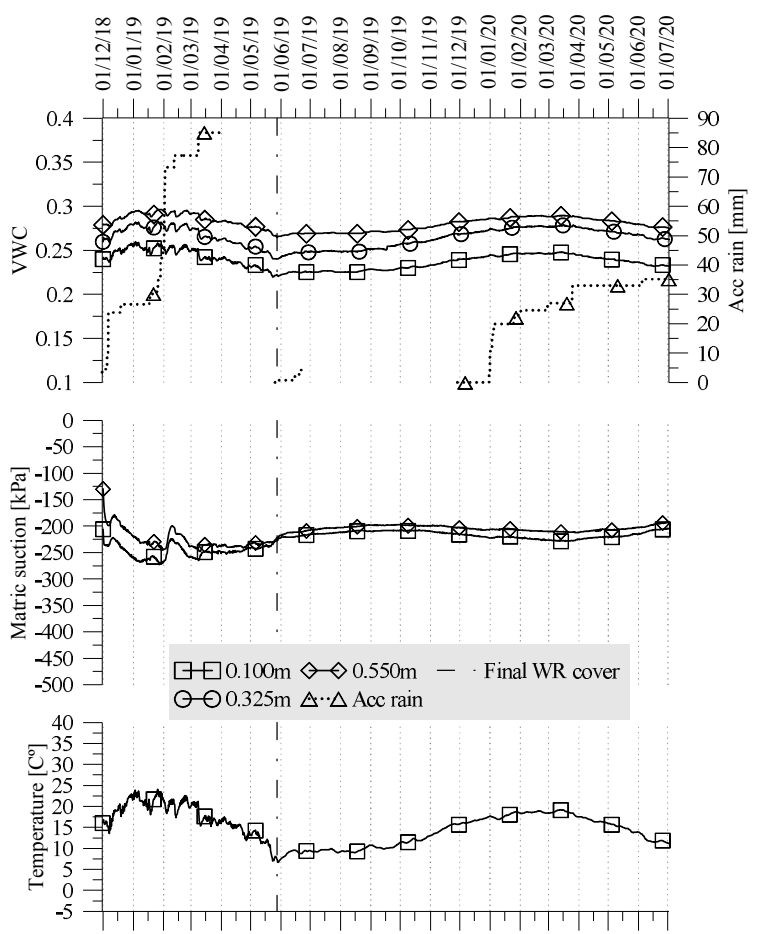

Fig. 8. Time evolution of VWC, matric suction and temperature recorded at different depthsof Plot 4

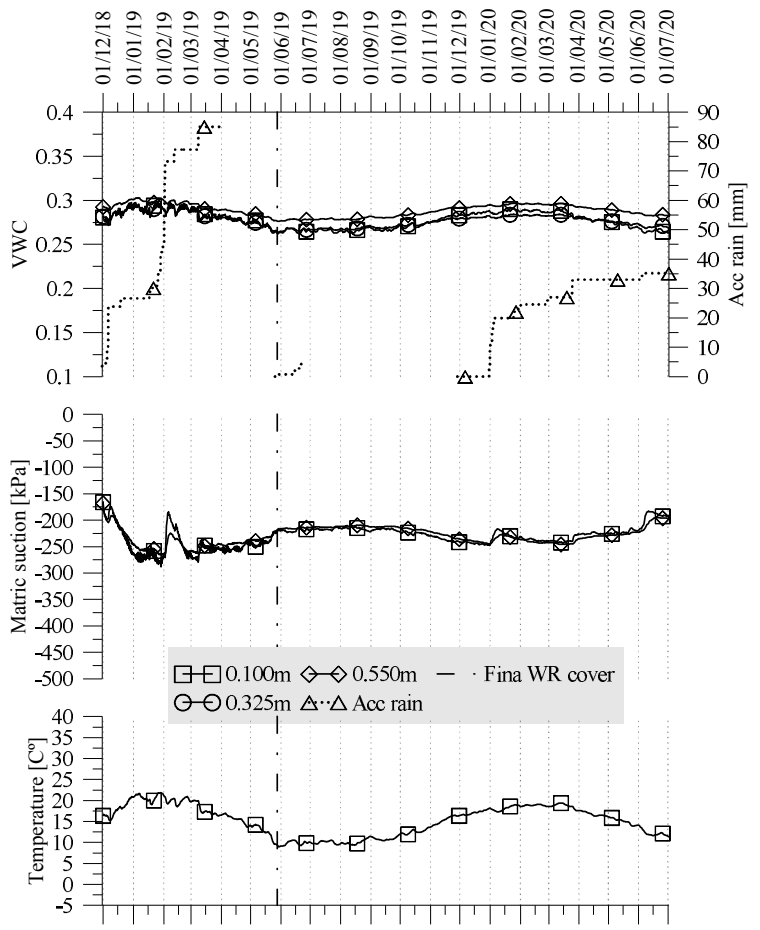

Fig. 9. Time evolution of VWC, matric suction and temperature recorded at different depths of Plot 5 


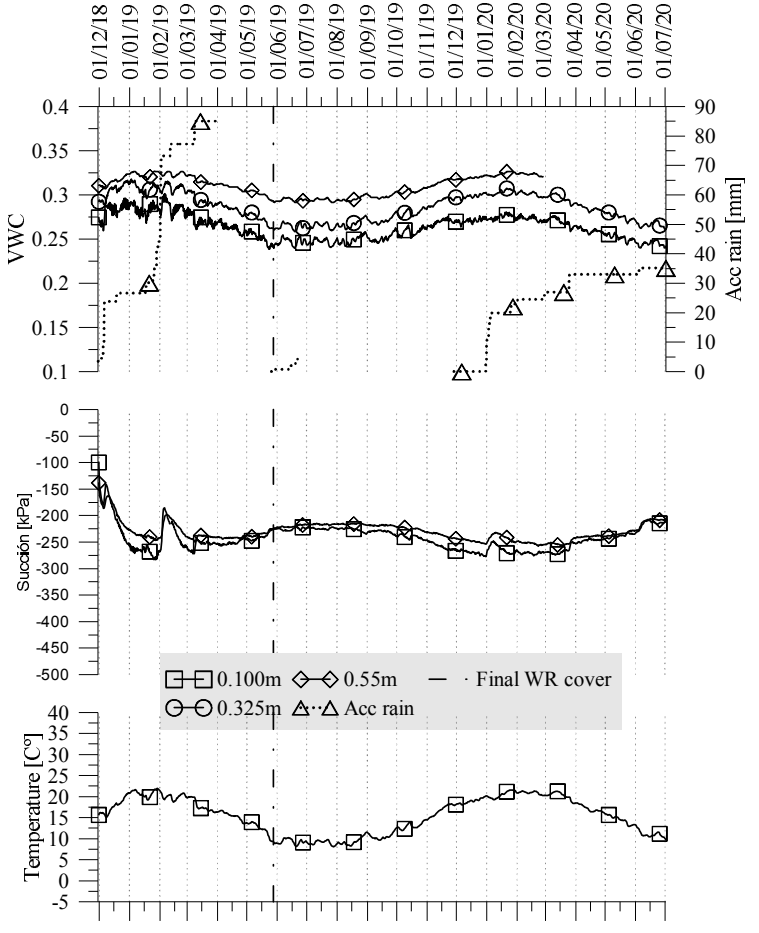

Fig. 10. Time evolution of VWC, matric suction and temperature recorded at different depths of Plot 6

\section{Analysis and conclusions}

The changes in drying tendency observed in plots 1 to 3 after rock waste placement shows that a rock waste layer of at least $50 \mathrm{~cm}$ thick precludes tailings water evaporation, by blocking the solar radiation and interfering with vapour diffusion, both key phenomena for tailings drying. Nonetheless, no VWC change is recorded as responses of plots 1 and 2 to rainfall throughout the recording period, thus implying that rock waste layers thickness covering these plots were sufficient to store the precipitation and avoid infiltration into tailings. The performance of rock waste acting as store-and-release layer by itself is unreliable, given its coarse, clean particle gradation. Typical pore size distribution of rock waste makes capillary raise of stored water unlikely, which implies that drying of rock waste layers may be slow and certainly depth limited. Thus, temporal distribution of rainfall or high previous water content may lead to rock waste storage capacity to be exceeded, so causing infiltration into tailings. The repetition of events causing rock waste storage capacity to be exceeded will cause tailings saturation, given that a $50 \mathrm{~cm}$ or thicker rock waste layer also precludes tailings drying.

Data from plot 3 shows that water from rainfall has been stored almost entirely in the shallowest portion of the tailings layer. Records also show that tailings storage capacity under test conditions is quickly restored after rainfall.

VWC and suction recorded at $55 \mathrm{~cm}$ depth of plot 3 after flooding test and rainfalls did not reach saturation. Consistently, records from percolating water measurement device installed at plot 1 resulted nil for the whole test period. On the other hand, nil percolation suggests non-significant preferential flow paths development at tailings, which may had shown up due to test set-up nature or shrinkage induced by later drying.

Water content of plots located at the slope of the stack remains practically constant during the whole test lapse, irrespectively of weather conditions. A possible explanation to such behaviour involves two main factors favouring a stationary drying front, namely the low ratio of exposed area/volume of the tailings and the placement of tailings in between of waste rock layers. The later design feature gives rise to capillary barrier effect at the interface between fine and coarse wastes, which prevents water from any tailings layer to freely flow to adjacent waste layers. Thus, during droughts virtually all the water stored at the entire volume of any tailings layer is available to flow by capillarity towards the exposed surface at the front of the slope. As a result, water content at the slope will reduce at such low rate that the effect over the test period is unnoticeable. During rainfalls, the steep surface of the slope and the limited tailings exposed area results in very low, hardly measurable infiltration.

As for the erosion protection objective, a visual inspection of waste rock layers over plot 3 and 6 , both $10 \mathrm{~cm}$ thick, after 13 months of weather exposure yields no signs of significant runoff damage, such as gullies, streams, ditches or waste rock falls. Neither wind erosion signs are seen.

Tough satisfactory, the conclusions about the performance of the cover prototype comprising a $10 \mathrm{~cm}$ thick waste rock layer presented herein have been derived from relatively scarce data, recorded during a low rainfall period when compared to site typical weather.

Being storage capacity of tailings dependent on own previous water content, the cover prototype performance may be different under other durations and/or temporal distributions of rainfall. Hence, to extend the applicability of this study it is necessary to evaluate the cover performance after extraordinary events, such as those associated with the stack closure stage life-span.

\section{References}

1. C. Wang, D. Harbottle, Q. Liu, \& Z. Xu. (2014). Current state of fine mineral tailings treatment: A critical review on the theory and practice. Minerals Engineering 58, 113-131.

2. D. Hillel. (1971). Soil and water: physical principles and processes. Academic Press, New York.

3. J. Stormont, C. Morris (1998). Method to estimate water storage capacity of capillary barriers. J Geotech Geoenviron Eng 124(6):297-303.

4. M. Khire, C. Benson, P. Bosscher. (2000). Capillary barriers: design variables and water balance. J Geotech Geoenviron Eng 126(8):695-708.

5. S. Cravero, C. Bianchi, H. Elena, A., Bianchi. (2017). Clima de argentina - mapas digitales mensuales de precipitación y precipitación menos 
evapotranspiración potencial - adenda del atlas climático digital de la república argentina. Salta, República Argentina. INTA Ediciones.

6. L. Oldecop, L. Garino, J. Muñoz, R. Rodríguez, C. García. 2010. Unsaturated behaviour of mine tailings in low precipitation areas. In Alonso, E. and Gens, A. (Eds). Unsaturated behaviour of mine tailings in low precipitation areas, Unsaturated Soils. Taylor \& Francis Group, London, 1425-1430.

7. L. Oldecop, G. Rodari, J. Muñoz. 2017. Atmosphere interaction and capillary barrier in filtered tailings. Geotechnical and Geological Engineering Journal 35(4):1803-1817.

8. Meter Group. 2020. https://www.metergroup.com/environment/products/ teros-21/. Accesed october 2020 .

9. Meter Group. 2019. http://publications.metergroup.com/Manuals/20435 5TE_Manual_Web.pdf. Accesed october 2020.

10. L. Walthert, P. Schleppi. 2018. Equations to compensate for the temperature effect on readings from dielectric Decagon MPS-2 and MPS-6 water potential sensors in soils. Journal of Plant Nutrition and Soil Science. (38): 749-759. 